\title{
GARGOYLISM : CLINICAL, RADIOLOGICAL AND HAEMATOLOGICAL FEATURES IN TWO SIBLINGS
}

\author{
BY \\ S. B. GRIFFITHS and M. FINDLAY \\ From the Department of Pathology, University of Natal, and King Edward VIII Hospital, Durban
}

(RECEIVED FOR PUBLICATION NOVEMBER 5, 1957)

Gargoylism is a rare disease. The complete form of this condition is easily recognized, but incomplete cases occur, and some of these are confused with the Morquio-Brailsford type of chondro-osteo-dystrophy. Most of the recorded cases have been in infants and children, and the early manifestations of this disease are well described by Caffey (1952). Fairbank (1951) states that, as a rule, gradual deterioration takes place and that the child dies before growth is complete. The expectation of life is much greater in incomplete varieties. Lindsay (1950) emphasizes the frequency with which the cardiovascular system is involved. The average age of gargoyle patients dying of cardiac failure is approximately 11 years, with a range of from 1 to 29 years. Cardiac hypertrophy is a striking feature, and there are pronounced lesions in the valves and the coronary arteries. He states that extra-cardiac factors probably contribute to cardiac embarrassment. The most important of these are thoracic deformity and chronic interstitial pneumonitis; the latter appears to be secondary to chronic nasopharyngeal inflammation. Extensive reviews of the clinical and radiological features of this condition are available. It is therefore unnecessary to repeat them.

The two cases to be reported seem to be the first described in non-whites in South Africa. The only cases previously reported from South Africa by McDonald and Opie (1951) and Jackson (1951) have been in individuals of European extraction. Townsend-Coles (1955) has noted three cases in children of the Northern Sudan.

\section{Case Reports}

Case 1. An Indian male, known as 'Tweedledum', was first admitted to King Edward VIII Hospital on August 30, 1954, at the age of 11 years. He was of stunted growth, height $3 \mathrm{ft} .8$ in. (Figs. 1 and 2). He was deaf and dumb, but of a happy disposition. He had a large dolichocephalic type of head on a very short neck. The facies were heavy, with a depressed bridge to the nose. His respiration was snorting, with open mouth, and he had a profuse nasal discharge. The congue constantly protruded: the tricuspid teeth were irregular and not in a straight row. The abdomen was protuberant, with everted umbilicus. Hirsutes was evident. There was gross hepatomegaly, but no splenomegaly. He could not extend the elbows freely, and could not raise the arms straight above the head. Flexion of all joints was full. The hands were claw-like. There was no obvious spinal deformity. Reflexes were all present, and motor power was good. There was no clouding of the cornea. The fundi were normal. There was no cardiomegaly; the pulse was 80 and regular. The heart sounds were closed.

LABORATORY EXAMINATIONS. The cerebrospinal fluid was normal. The serum cholesterol was $173 \mathrm{mg}$. \%. The serum calcium was $11 \cdot 1 \mathrm{mg}$. \%. The serum alkaline phosphatase was 19 K.A. units. Kolmer complement fixation tests on blood and cerebrospinal fluid were negative. The haematological features will be discussed separately.

Case 2. An Indian male, known as 'Tweedledee', was aged 10 years at the time of admission with his brother and was slightly taller. He had an identical configuration, and exhibited very similar features. Hirsutes was marked (Figs. 1 and 2). He was mentally alert, showing an eager interest in his surroundings and was always the instigator in the two's activities. He exhibited night blindness. He was not completely deaf, and was able to speak, though not very distinctly. There was no clouding of the cornea and the fundi were normal. He had signs of upper respiratory catarrh. There was no cardiomegaly.

Laboratory findings were very similar to those of his brother and were non-contributory.

\section{Radiological Features}

These were almost identical in the two siblings. The radiographs illustrated are those of Case 1.

Skull. This showed some degree of hydrocephalus, with a dolichocephalic configuration. The pituitary fossa 


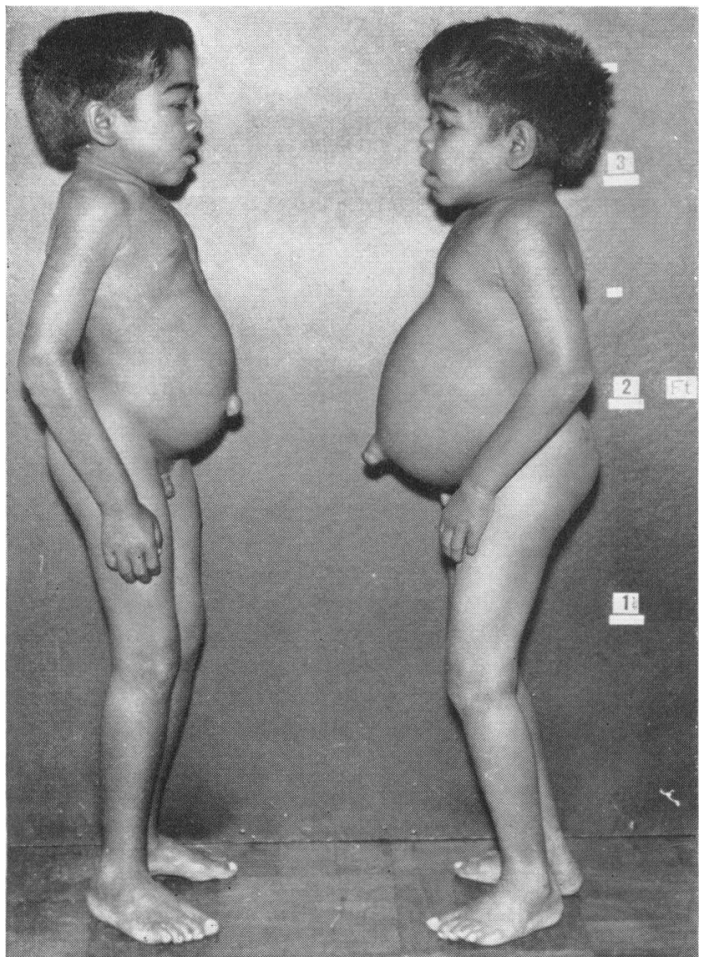

FIG. 1.-The brothers, aged 10 and 11 years.

was not obviously enlarged, but the posterior clinoid processes were long (Fig. 3). There was some bulging of the temporal regions. The mandibles appeared slightly enlarged.

Spine. Some of the dorso-lumbar vertebrae were biconvex, and a few vertebrae showed very slight beaking at the lower anterior angles. There was no abnormal kyphosis, and no hypoplasia of the vertebral bodies.

The ribs appeared thicker than normal. The glenoid fossae were shallow.

Upper Limbs. The long bones appeared somewhat tubular, the diaphyses being about the same width as the metaphyses. There was bowing of the radii, and the distal ends of the metaphyses of the radii and ulnae sloped towards each other. Ossification of the wrist bones and carpal bones was delayed. The metacarpals and phalanges were tubular, with a thin cortex, and there was slight pointing of the proximal ends of the metacarpals. The terminal interphalangeal joints of both hands were flexed (Fig. 4).

Lower Limbs. The capital femoral epiphyses were flattened, and there was a coxa valga deformity. The acetabula did not appear shallow. The cortex of the

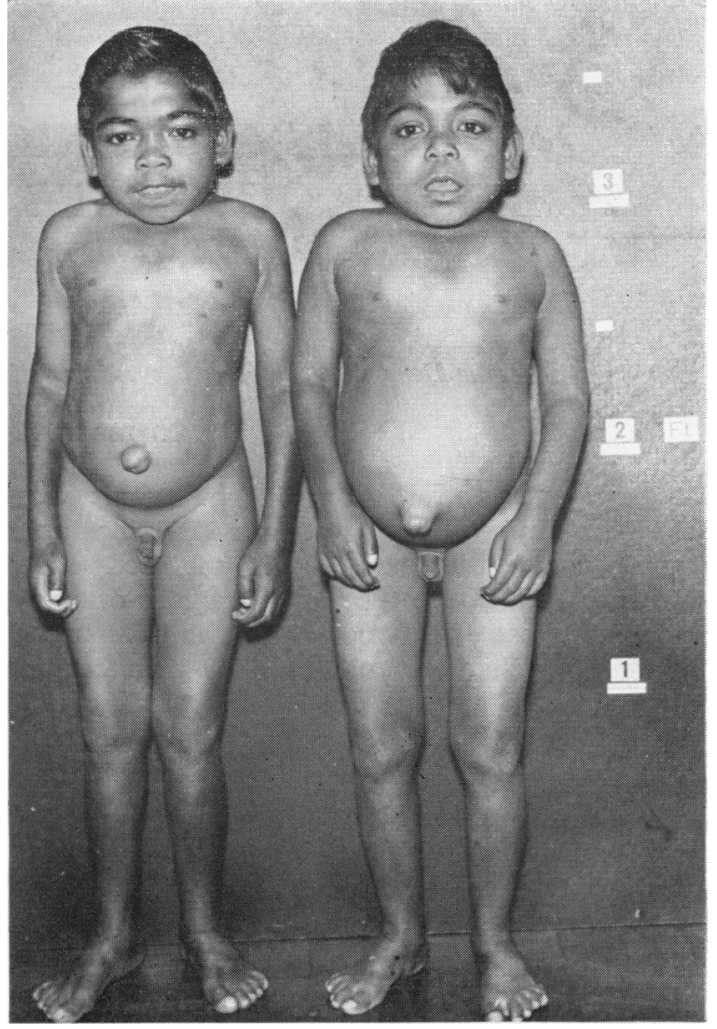

FIG. 2.-The brothers, at the same age as in Fig. 1.

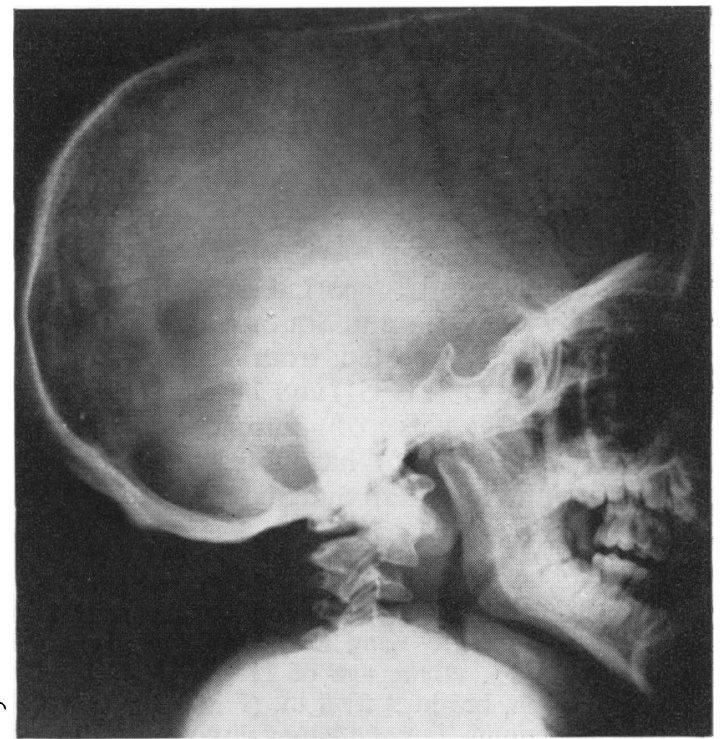

FIG. 3.-Dolichocephalic skull, with elongated posterior, clinoid processes. 


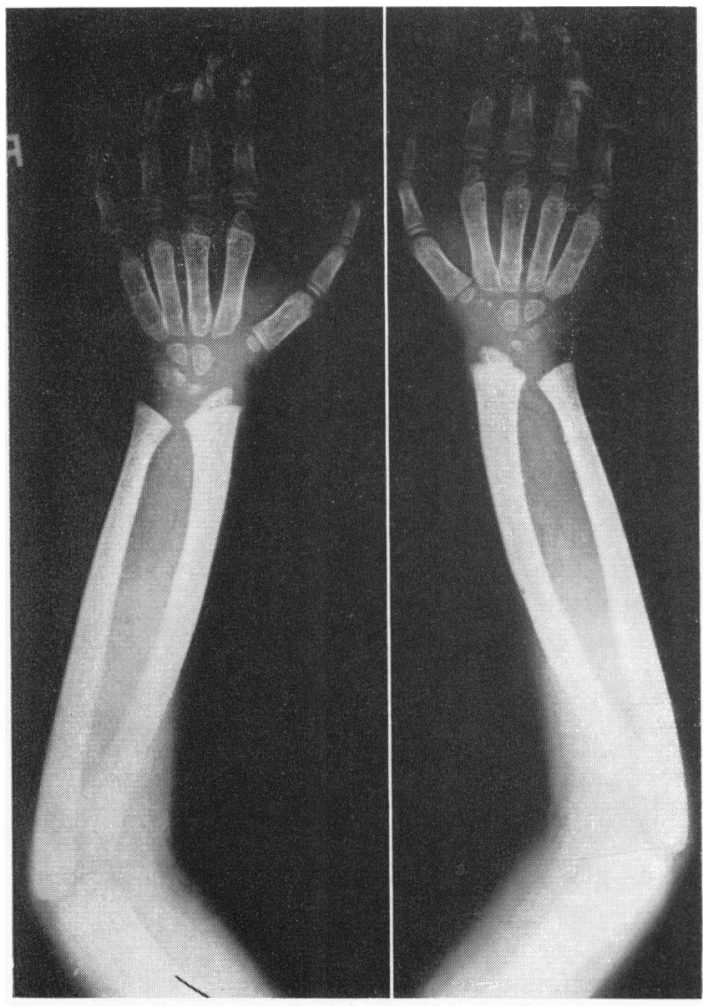

FIG. 4.

lower ends of the femora was thinned and the bones had a shape similar to that seen in Gaucher's disease. The feet showed slight changes similar to those of the hands.

Heart and Lungs. There was some increase of the pulmonary vascular shadows, and prominence of the pulmonic arc. There was no enlargement of the heart at the first examination (Fig. 5). On re-examination approximately two years later cardiomegaly was demonstrated, with marked increase in the prominence of the pulmonic arc, suggesting cor pulmonale (Figs. 5 and 6).

Although the clinical features of these cases are well developed and diagnostic, the radiological features are relatively slight. Retardation of growth is not marked. The upper limbs are not shortened, and the degree of deformity of the shafts of the long bones is not striking. The vertebral changes are very much less obvious than in many reported cases. All the findings, however, are in conformity with the changes described in gargoylism.

FIG. 4.-Showing the flexed terminal interphalangeal joints, the tubular shape of the phalanges and metacarpals, the pointed bases of the metacarpals, the abnormal slope of the distal metaphyses of radii and ulnae and bowing of radii.

FIG. 5.-No cardiomegaly; slight increase of the pulmonary vascular shadows and slight prominence of pulmonic arc.

FIG. 6.-Cardiomegaly with marked increase in prominence of pulmonic arc.
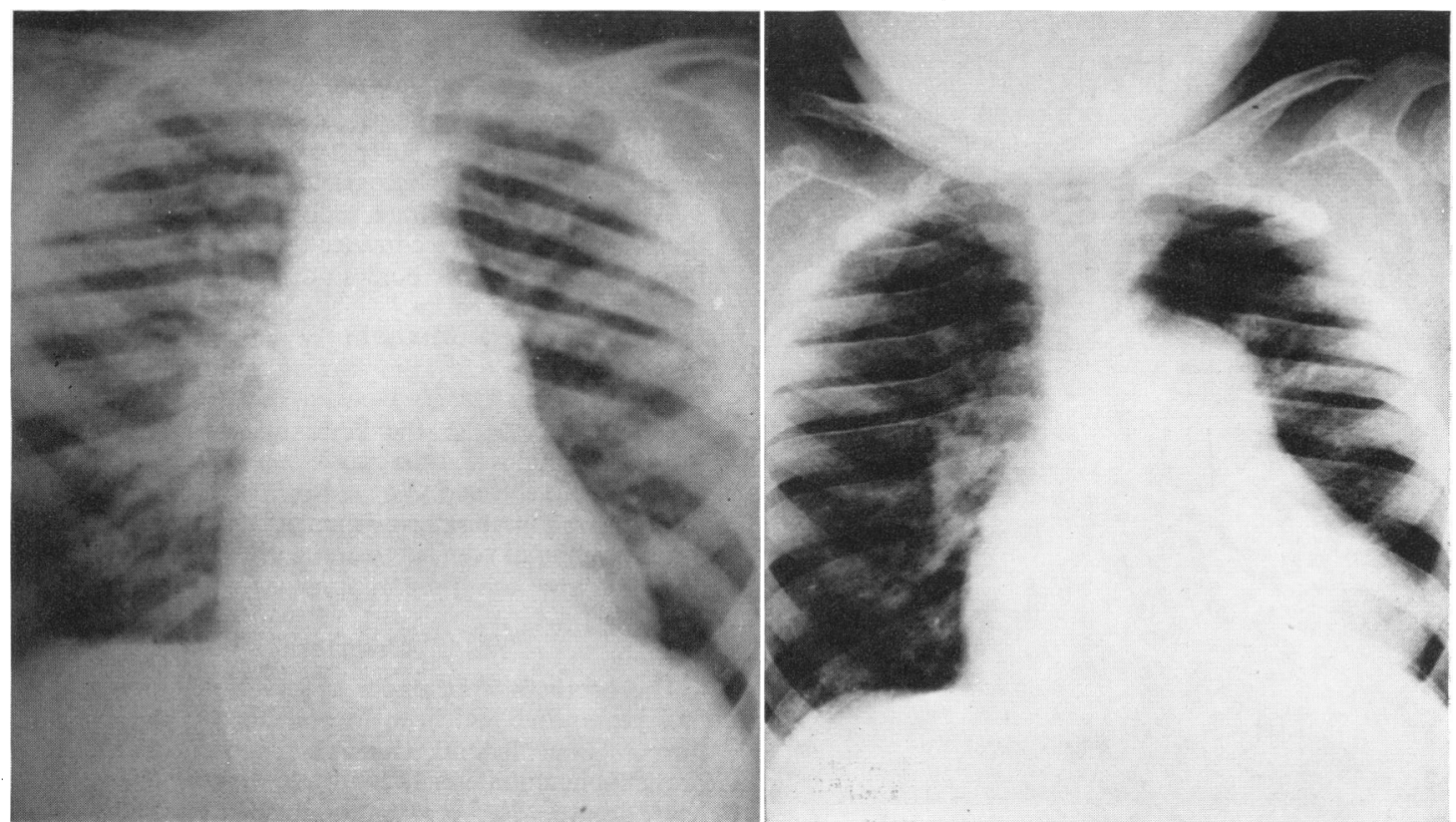

FIG. 5 


\section{Haematological Findings}

The peripheral bloods of the two cases were virtually normal. Alder's (1939) anomaly, which consists of a purple staining granulation of the cytoplasm of the polymorphonuclears, lymphocytes and monocytes, was searched for but was not found. This, however, is not surprising as, in spite of some reports, only a moderate number of cases of gargoylism show any abnormality of the white cells of the circulation (McKusick, 1956; Reilly and Lindsay, 1948).

Sternal punctures were performed on both patients. Great difficulty was experienced in piercing the extremely tough skin over the sternum, but good samples of marrow were obtained. The marrow particles were of normal cellularity and leucopoiesis and erythropoiesis were normal. Again Alder's anomaly was not observed, in spite of a prolonged search. The most striking feature of the films, which were stained by the May-Grunwald Giemsa technique, was the presence of numerous large cells distended with many very dark purple-staining masses of varying size. These granules, the largest of which were $1-2 \mu$ in diameter, almost completely obscured the outline of the cells, and partially obscured the nuclei. Similar masses of granular material were also found lying free, presumably originating from cells ruptured in smearing. The cells containing these granules were considered to be histiocytes and are shown in Fig. 7.

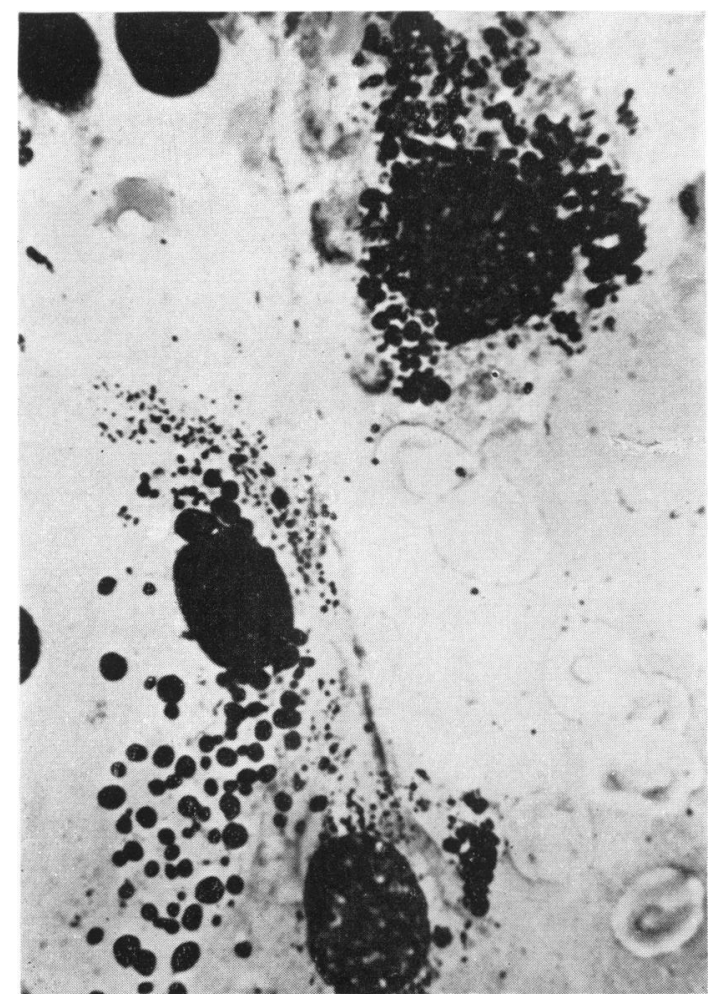

FIG. 7.-Histiocytic cells showing masses of darkly staining material. This resembles the type of cell described by Gasser.

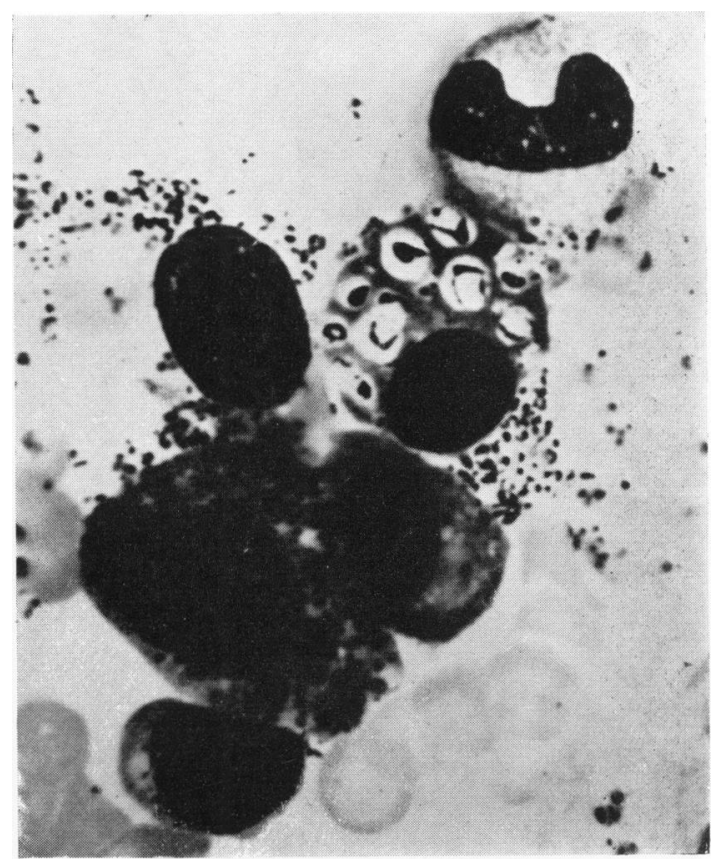

FIG. 8.-Ring-like bodies in clear vacuoles found in cytoplasm of plasma cells.

They were found in the marrow of both patients and are considered to be identical with those described in a case of gargoylism by Gasser (1950).

In addition to this abnormality, further extraordinary inclusions were observed. They were dark purplestaining ring-shaped bodies approximately $1 \mu$ in diameter with clear centres, which were found in vacuoles in the cytoplasm of cells, believed to be plasma cells. They are shown in a microphotograph (Fig. 8).

We were unable to trace reports of similar findings in the literature, and we consider them to be quite distinct from the inclusion bodies described previously as occurring in gargoylism.

These cells were present in the marrows of both cases. In September, 1956, the bloods of these cases were re-examined by Dr. J. Duncan-Taylor who found the same phenomena in the bone marrow. Attempts to stain the granules and the ring-like bodies using Nile-blue sulphate and the periodic acid-Schiff method on formol vapour fixed material were unsuccessful. At no time was the material allowed to come in contact with alcohol or xylol and the preparations were examined under water.

\section{Progress}

The brothers were under observation for two and a half years, and had been in and out of hospital many times. 'Tweedledum', the elder, had three attacks of bronchopneumonia in 18 months, and developed chronic heart failure. He became dyspnoeic at rest. There was slight ankle oedema. The liver was enlarged to the 
umbilicus, and there was some enlargement of the spleen. The blood pressure was $120 / 90 \mathrm{~mm}$. Hg. An electrocardiogram showed right ventricular strain and hypertrophy. The heart became enlarged, with the apex beat in the fifth interspace between the nipple line and the anterior axillary line. There was a blowing systolic murmur at the apex, conducted to the axilla. The pulmonary second sound was accentuated with a soft systolic murmur. He died in March, 1957, from acute cardiac failure. Permission for necropsy could not be obtained.

'Tweedledee', the younger, was always admitted to hospital with his brother because they were inseparable, He has had one attack of bronchopneumonia in the last 18 months. He is not in congestive cardiac failure, and has not developed cardiomegaly. He has dyspnoea on slight exertion. Hepatomegaly is fairly marked, but there is no sign of splenomegaly.

The mother of the children has recently been interviewed, but she was a bad witness, and little information could be obtained as to the earlier history of the siblings. She had two normal children, one about 19 years and the other 9 years old.

\section{Aetiology and Pathogenesis}

The aetiology and pathogenesis of this comparatively rare disease is a matter of controversy. The term lipochondrostrophy suggested by Washington (1937) indicated the current view that the disease was a disorder of lipid metabolism associated with skeletal deformities. In a recent review by Creveld (1953) it is still classified amongst the lipoidoses, although current work suggests that the abnormal substance present in the tissues is not a lipoid. The disease was considered to be a lipoid storage disease by Ellis, Sheldon and Capon (1936) and by Henderson (1940).

The essential lesion of the disease is the accumulation, in various parts of the body, of cells containing an abnormal substance, and the bizarre clinical features of the disease can be attributed to the resulting disturbance of structure and function of the affected tissue. The chemical composition of this stored material has been the subject of several recent papers but its nature is still undecided. One of the difficulties is that only a small number of cases have had biopsies or autopsies performed, and no investigator has had material from more than three or four cases to examine. It is possible that the condition is a syndrome which may be caused by the accumulation of more than one substance, thus accounting for the varying results reported. This would also account for the variation in the clinical features of some reported series; and there is increasing recognition of 'incomplete' forms, some of which can only be differentiated with difficulty from similar conditions such as Morquio-Brailsford disease (Kammerer, Mathis and Wackenheim, 1955).
The injection of macromolecular substances of varying chemical nature into experimental animals can produce extensive anatomical changes (Hueper, 1942) but so far the syndrome of gargoylism has not been produced.

Lindsay, Reilly, Gotham and Skahen (1948) thought that the stored material in gargoylism was a glycogen-protein complex. Brante (1952), in a study based on three cases in which he isolated a lipid and a non-lipid fraction, thought the disease was mucopolysaccharidosis. Uzman (1955) reported the isolation of a polysaccharide and a glycolipid fraction. He considered the disease was not caused by the accumulation of these substances, but as a result of a defect in the synthesis of polysaccharide which is known to be intimately concerned with the synthesis of collagen.

Even if it is accepted that the symptomatology of the disease is due to a metabolic defect, there is also evidence that hereditary factors are important in its development. The usual influences which increase the incidence of foetal abnormalities have not been shown to operate in this disease. Maternal age, trauma, disease or state of parity are unimportant. An endocrine factor functioning either directly or as a potentiating influence has been suggested by some (Kammerer et al., 1955), but there is little to substantiate this. Most authors agree that there is a high incidence of families with more than one affected child. Lindsay et al. (1948) cite the family described by Böcker (1943) in which there was an affected child in each of four generations who were direct descendants of one unaffected woman. There was also one girl showing signs of Morquio disease in the third generation. Halperin and Curtis (1942) considered that the occurrence of affected individuals could be explained by its being determined by a single autosomal gene. Jervis (1950) in whose series 26 of the 85 families studied had two or more affected members, considered that the numbers were consistent with the condition being due to a single recessive gene. This would only hold if there was a high incidence of cousin marriages. In 11 of 103 families the parents were cousins. A sex linked form has been described (Millman and Whittick, 1952) and single members of binovular twin pairs have been affected, while the other twin has been unaffected. (Lindsay et al., 1948). There is thus strong evidence for gargoylism being a hereditary defect, and McKusick (1956) goes as far as to say that there are at least two genotypes of this disease which can be distinguished clinically.

The two cases described show a remarkable similarity to each other, but whilst the clinical picture closely resembles the classical descriptions 
of the disease, the radiological features are less marked than might be expected. The blood findings, too, are unusual, and have not hitherto been described. This again emphasizes the probability that different types of the disease exist. Possibly there are different underlying mechanisms which can produce closely similar syndromes.

\section{Summary}

Gargoylism in two brothers is described. They appear to be the first cases of this condition recognized in individuals of Indian extraction. The clinical, radiological and unusual haematological findings are described and discussed. Granular inclusions in the bone marrow histiocytes were present, and hitherto undescribed ring-shaped inclusions were present in the plasma cells of the bone marrow.

We wish to thank Dr. S. Disler, Superintendent of King Edward VIII Hospital, for permission to publish these cases, Dr. Rossiter, under whose care they were admitted, and Mr. C. R. Stuart, of the Department of Pathology, University of Natal, for the photographs.

\section{REFERENCES}

Alder, A. (1939). Dtsch. Arch. klin. Med., 183, 372.

Böcker, E.(1943). (Cited by Lindsay et. al.) Z.Kinderheilk., 63, 688. Brante, G. (1952). Scand. J. clin. Lab. Invest., 4, 43.

Caffey, J. (1952). Amer. J. Roentgenol., 67, 715 .

Creveld, S. van (1953). Advances Pediat., 6, 223.

Ellis, R. W. B., Sheldon, W. and Capon, N. B. (1936). Quart. J. Med., n.s. 5, 119.

Fairbank, H. A. T. (1951). An Atlas of General Affections of the Skeleton. Edinburgh.

Gasser, C. In discussion of paper by Alder, A. (1950). Schweiz. med. Wschr., 80, 1097.

Halperin, S. L. and Curtis, G. M. (1942). Amer. J. ment. Defic., 46, 298.

Henderson, J. L. (1940). Arch. Dis. Childh., 15, 201

Hueper, W. C. (1942). Arch. Path. (Chicago), 33, 267.

Jackson, W. P. U. (1951). Arch. Dis. Childh., 26, 549.

Jervis, G. A. (1950). Arch. Neurol. Psychiat. (Chicago), 63, 681.

Kammerer, T., Mathis, M. and Wackenheim, A. (1955).'Presse méd., 63, 1386 .

Lindsay, S. (1950). Brit. Heart J., 12, 17.

Lindsay, Reilly, W. A., Gotham, T. J. and Skahen, R. (1948). Amer.

- Reilly, W. A., Gotham, T. J. and Skahen, R. (1948). Amer.
J. Dis. Child., 76, 239.
McDonald, R. and Opie, W. H. (1951). S. Afr. med. J., 25, 725.

McKusick, V. A. (1956). J. chron. Dis., 3, 360.

Millman, G. and Whittick, J. W. (1952). J. Neurol. Neurosurg. Psychiat., 15, 253.

Reilly, W. A. and Lindsay, S. (1948), Amer. J. Dis. Child., 75, 595.

Townsend-Coles, W. F. (1955). Arch. Pediat., 72, 283.

Uzman, L. L. (1955). A.M.A. Arch. Path., 60, 308.

Washington, J. A. (1937). In Brennemann's Practice of Pediatrics, Vol. IV. Hagerstown, Maryland. 